International Journal of Advanced Trends in Computer Science and Engineering

Available Online at http://www.warse.org/IJATCSE/static/pdf/file/ijatcse2781.32019.pdf

https://doi.org/10.30534/ijatcse/2019/2781.32019

\title{
Moisture Susceptibility of Modified Asphalt Concrete Containing Titanium Dioxide
}

\author{
Rosnawati Buhari ${ }^{1}$, Mohd Ezree Abdullah ${ }^{2}$, Mohd Khairul Ahmad ${ }^{3}$, Nurfareesya Zabidi ${ }^{4}$, \\ Siti Khatijah Abu Bakar ${ }^{5}$ \\ 1,2,45Faculty of Civil and Environmental Engineering, Universiti Tun Hussein Onn Malaysia, Batu Pahat, Johor, \\ Malaysia,rosna@uthm.edu.my \\ ${ }^{3}$ MINT-SRC, Universiti Tun Hussein Onn Malaysia, Batu Pahat, Johor, Malaysia
}

\begin{abstract}
The aim of this research was to establish the asphaltic mixture using modified nano-titanium dioxide $\left(\mathrm{TiO}_{2}\right)$ modified binder according to Superpave mix design method. The specimens were mix with $5.7 \%$ bitumen content at desire temperature and compacted by using Superpave mix design and evaluated for the moisture sensitivity according to Modified Lottman Test. The result shows that the specimens with $8 \%$ additive have significantly higher ITS and better resistance to water damage with lower air void. Furthermore, the ITSR results indicate that specimens containing $6 \%$ additive exhibited higher were the value $91.44 \%$ compared with the control specimen. All in all, modified nano- $\mathrm{TiO}_{2}$ is suitable to be used as additive in warm mix asphalt and extend lab testing should be conducted to further understanding the characteristics of nano- $\mathrm{TiO}_{2}$ modified binder and mixes.
\end{abstract}

Key words : Titanium Dioxide, modified asphalt, moisture susceptibility.

\section{INTRODUCTION}

Moisture damage is a factor affecting the durability and strength of asphalt pavement due to presence of water. Water causes loss of adhesion at the bitumen-aggregate interface. According to Hamzah et al. stripping also referred to a moisture damage that occurs due to loss of bonding between the asphalt and aggregate[1]. Too much moisture in asphalt can contribute to the overfilling of the voids and prevent good coating of the aggregate by asphalt can making the mixture unstable. Other than that, water entrapped inside the asphaltic mixture can increase the pressure and finally can causes damages. The aggregate that is not fully dry from moisture will reduce bonding amongst aggregate and binder[2].

Moisture susceptibility is an issue that commonly prompts the stripping of the binder from the aggregate and stripping influences the asphalt mixture ravels and deteriorate. Besides that, construction factor that contributed to moisture damage included the quality of compaction and weather condition during pavement construction and control air voids was generally considered the most important construction factor. Other than that others researchers claimed that there are have six contributing factors that can causing moisture damage in HMA there are detachment, displacement, spontaneous emulsification, pore-pressure-induced damage, hydraulic scour and environmental effects [3]. In order to improve the performance of virgin asphalt binder to an ideal asphalt binder, the virgin asphalt binder needs to be modified with suitable modifiers [4].

Many researches had found that nano-materials shown its effectiveness through the modification of virgin asphalt binder with certain portion and it have significant effects in improving the engineering properties of asphalt binder and mixture [5]. In this study, titanium dioxide $\left(\mathrm{TiO}_{2}\right)$ and different type of commercial titanium dioxide will be used as modifier in warm mix asphalt to observe the change of properties of bitumen and mixture of warm mix asphalt. Titanium dioxide has been known to be one of the popular nano-materials in bitumen construction asides from nanosilica, nanoclay, and carbon nanotubes. Titanium dioxide presents in three crystalline formed namely rutile, anatase and brookite. Anatase $\mathrm{TiO}_{2}$ shows greater photocatalytic activity in compared with rutile due to its activeness in reacting to chemical. It in high viscosity, bitumen can rarely be used in its raw form at ambient temperatures [6]. Nano- $\mathrm{TiO}_{2}$ possesses the same characteristic as normal sized $\mathrm{TiO}_{2}$, the difference is only on the size of the particle and the increased contact surface. As the catalytic process is enhanced too, therefore its performance on asphalt binder should be observed and evaluated.

Nano-materials are currently utilised extensively to improve the performance in pavement research especially on modification of asphalt binder for flexible pavement. Much of the work to date in flexible pavement engineering involved the modification of virgin asphalt binder with various types of nano-materials such as nanoclay, nanohydrated lime and carbon nano perticles. Meanwhile, in rigid pavement, study on the implementation of nano-material only focused on modification of surface treatment of concrete layer using nano titanium oxide $\left(\mathrm{TiO}_{2}\right)$.

\section{EXPERIMENTAL METHODS}

In this experimental study, bitumen of penetration grade $80 / 100$ is used together with modified nano- $\mathrm{TiO}_{2} \mathrm{P} 25$ of $2 \%$, $4 \%, 6 \%, 8 \%$ and $10 \%$ by weight of bitumen. The mixing of the sample is made with $500 \mathrm{~g}$ bitumen and the mixing speed is $3500 \mathrm{rpm}$, for duration of 30 minutes at $155^{\circ} \mathrm{C}^{7}$. To conduct the mixing, $500 \mathrm{~g}$ of bitumen is placed inside an aluminium 
can and placed inside the heavy duty oven at $155^{\circ} \mathrm{C}$ for approximately half hour, then it is transferred to a hot plate and the temperature of the sample is made sure always constant at $155^{\circ} \mathrm{C}$, specified amount of modified nano- $\mathrm{TiO}_{2}$ is added gradually into the bitumen as the high shear asphalt mixer is rotating at specified speed for 30 minutes. For penetration test the preparation of samples according to ASTM D5[8]. Asphalt binder was heated up at a temperature of $90^{\circ} \mathrm{C}$ until it becomes pouring consistency and stirred up slowly until it was homogeneous and free from entrapped bubbles and moisture. $50 \mathrm{~g}$ of melted sample was poured into a container. The sample was protected from dust and it was allowed to cool down at a temperature between $15^{\circ}$ to $30^{\circ} \mathrm{C}$ for one hour. It was then placed along with the transfer dish in the water bath at $25^{\circ} \pm 0.1^{\circ} \mathrm{C}$ for 1.5 hours before the test. Next, the sample was penetrated on the surface with a dimensionless needle in approximately for $5 \pm 0.1$ seconds. The loaded is $100 \pm 0.05$ grams and the testing temperature is maintained at $25 \pm 0.1^{\circ} \mathrm{C}$.

The procedure softening point is referring to ASTM D $36^{9}$. Dimensioned brass rings poured with asphalt binder and let it stayed at room temperature for approximately 30 minutes before trimmed. After 30 minutes maintained at the same temperature, the rings and assembly and two ball bearings was placed in a liquid bath filled to a depth of $105 \pm 3 \mathrm{~mm}$ and the temperature of $5 \pm 1^{\circ} \mathrm{C}$ for 15 minutes. The testing was done hereafter by strictly following a limit of temperature increases for every single temperature increases as listed in the procedure. It is highlighted that the temperature gap between a dropped of both steel balls are less than $1^{\circ} \mathrm{C}$. It is noticed that, behavior of binder was changing from solid to liquid as the temperature rises. The consistency is similar for different grade of binders at their softening point temperatures regardless the grade of the binder.

For preparing fatigue test samples, it starts with determining the optimum bitumen content. The optimum binder content (OBC) of the sample is prepared using the nominal maximum aggregate size (NMAS) of $9.5 \mathrm{~mm}$. The OBC are determined according to the AASHTO T312 procedure published by Asphalt Institute's Superpave Mix Design, SP-2, third edition, "Preparing and Determining the Density of Hot Mix Asphalt (HMA) Specimens by means of the Superpave Gyratory Compactor" and AASHTO policies, PP-28-2000, Standard Practice for Superpave for Superpave Volumetric Design for Hot Mix Asphalt [10]-[11]. The mixture design is based on medium to high category of load level which is equivalent between 3 to less than 30 million Equivalent standard axle loads.

The Indirect tensile test is one of the common tests conducted on asphaltic mixture specimens to detect moisture damage[12]. In fact, it has been adopted by AASHTO and Superpave mix design procedure. The control sample was tested without moisture conditioning known as dry sample. The dry subsets were stored at room temperature for 24 hours. Before running the test, the samples were placed in an incubator for preconditioned specimen at $25^{\circ} \mathrm{C}$ for 2 hours. The wet subsets are placed into vacuum container to condition the sample about 10 minutes until it gets between $70-80 \%$ degrees of saturation. Then after get the saturation, all samples were immersing $60^{\circ} \mathrm{C}$ in water bath for 24 hours. Next, the specimens are placed in the $25^{\circ} \mathrm{C}$ water bath for 2 hours with a $25 \mathrm{~mm}$ of water above the surface of specimen. The samples then are tested for Indirect Tensile Strength (ITS). Loaded the specimen at a constant rate of 50.0 $\mathrm{mm} /$ minutes with vertical deformation at $25^{\circ} \mathrm{C}$ and measured the force required to break the specimen. To determine the tensile strength ratio (TSR), the indirect tensile strength of the conditioned specimens is compared to the control specimens and the ITS value must not less than $80 \%$.

\section{EXPERIMENTAL RESULTS}

\subsection{Penetration and Softening Point Test}

Figure 1 and Figure 2 show results of penetration and softening point tests respectively. The addition of nano- $\mathrm{TiO}_{2}$ into control binder given a satisfying result in decreasing the penetration value compared to original binder from approximately 96.3 to 56.42 for control and BT10 respectively. The decrease in penetration indicates improvement of the binder stiffness which is an important factor in modified binder property. Softening point test is a measure of the temperatures at which phase change occurred in asphalt materials [13]. Higher softening point indicates stiffer bitumen and lower temperature susceptibility at high temperature, which is more preferred in hot climates. Addition of additive into the asphalt of penetration grade $80 / 100$, the softening point is slightly higher than the control bitumen from 42.97 to 45.18 for control and BT10 respectively. The overall softening points for the various concentration of nano- $\mathrm{TiO}_{2}$ modified bitumen are in a small range which indicates that $\mathrm{TiO}_{2}$ has little impact in rising the softening point. In general, the increasing values of softening of nano- $\mathrm{TiO}_{2}$ modified binder demonstrate the increased hardness and stiffness of the binder which is desirable in asphalt industry.

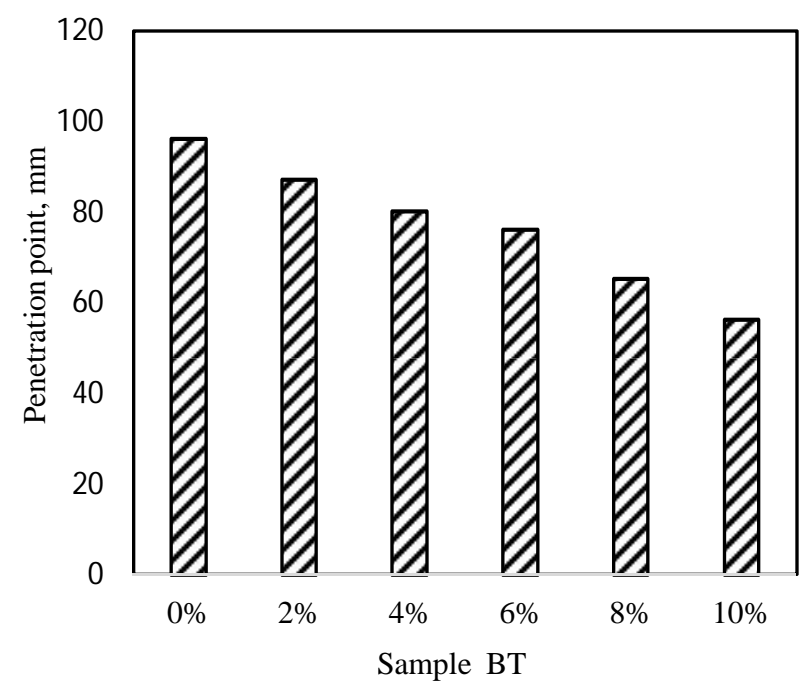

Figure 1: Penetration test results 


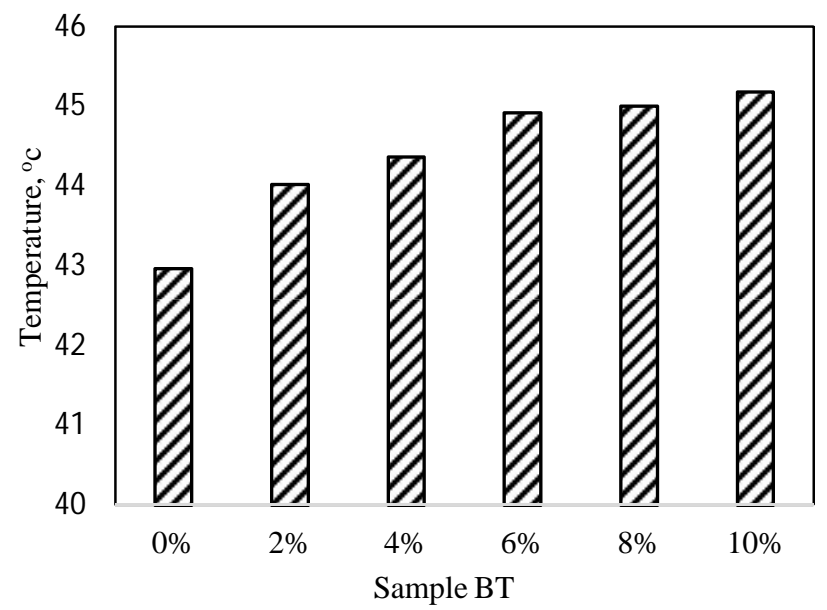

Figure 2: Softening point test results

\subsection{Indirect Tensile Strength Test}

In this research, the resistance from the moisture damage of modified asphalt containing various percent of modified nano- $\mathrm{TiO}_{2}$ had been evaluated by using indirect tension test. The ready sample with $95 \pm 5 \mathrm{~mm}$ diameter, $63.5 \pm 2.5 \mathrm{~mm}$ thick and $7.0 \pm 0.5 \%$ air void was prepared to test by using Marshall testing apparatus maximum load applied indirectly to the conditioned and unconditioned samples. The air voids can be obtained by adjusting the number of blows, adjusting foot pressure, number of tamps, leveling load or adjusting the number of revolutions. All specimens are in a range 6.5 to $7.5 \%$ and comply with the AASHTO T283 specifications requirement.

Figure 3 shows the ITS result for compacted specimens prepared with difference binder content. By using different binder content, the ITS value for control is higher than other binder content. The results shows value of ITS dry and wet specimens of each binder contents are decrease respectively. The bar chart demonstrates the values of ITS depends on the percent of binder content used. The tensile strength of wet sample was lower as compared to dry samples. This is because the presence of water will reduce the tensile strength of the mixture. The modified asphalt with $4 \%$ of nano- $\mathrm{TiO}_{2}$ had the higher strength for dry sample, $62.71 \mathrm{kPa}$. Moreover, $2 \%$ of nano- $\mathrm{TiO}_{2}$ of modified asphalt of wet sample shown the higher strength approximately $49.91 \mathrm{kPa}$ compared to other sample although it is in wet condition. A $10 \%$ of nano- $\mathrm{TiO}_{2}$ of modified asphalt of wet sample shows the lower value of strength approximately $43.94 \mathrm{kPa}$. It was happen may be because sensitivity to the temperature during the testing that make the loss of asphalt adhesion and cohesion make entering of water between the void of asphalt and binder. The specimens with $8 \%$ additive have significantly higher ITS and better resistance to water damage with lower air void. Here, we can conclude that, the present of nano- $\mathrm{TiO}_{2}$ cause the asphalt to sustain higher strength and reducing the moisture damage.

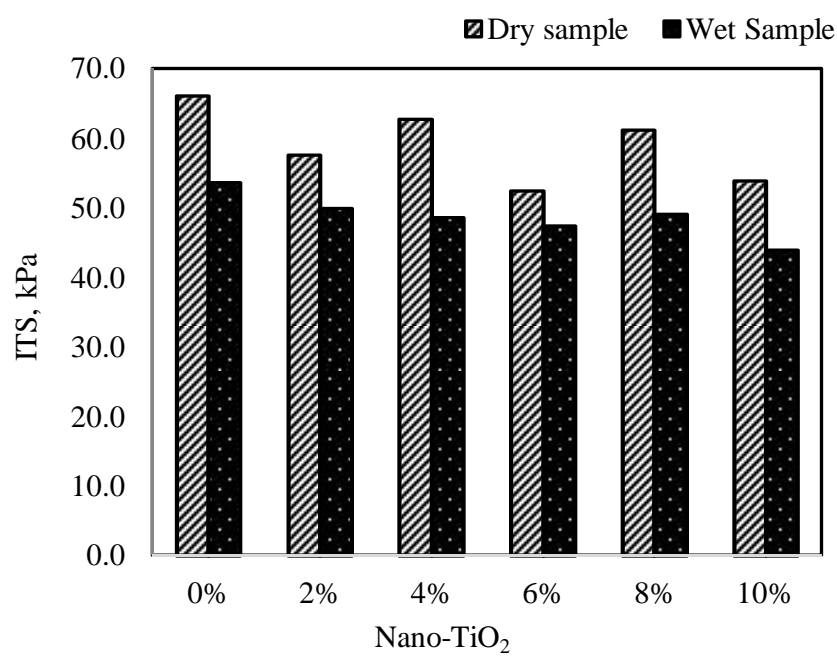

Figure 3: Indirect tensile strength of different percentage of additive

The Indirect Tensile Strength Ratio (ITSR) test was performed to measure the resistance of water sensitivity of asphalt mixtures with difference binder content. Figure 4 show the average ITSR, which is defined as the ratio ITS of wet specimen over dry specimen. It is observed that the ITSR for all specimen of difference binder was non uniform. ITSR for all modified asphalt was passed based on the standard requirement and where also is considered more than $80 \%$ and accept for $4 \%$ where $77.42 \%$.

Furthermore, the ITSR results indicate that specimens containing $6 \%$ additive exhibited higher were the value $91.44 \%$ compared with the control specimen. Modified asphalt has a tendency to prolong the pavement life compared to conventional asphalt. The using of modified nano- $\mathrm{TiO}_{2}$ in asphalt mixes shown that the moisture damage can be reduces even though the temperature of mixing and compaction was reduced.

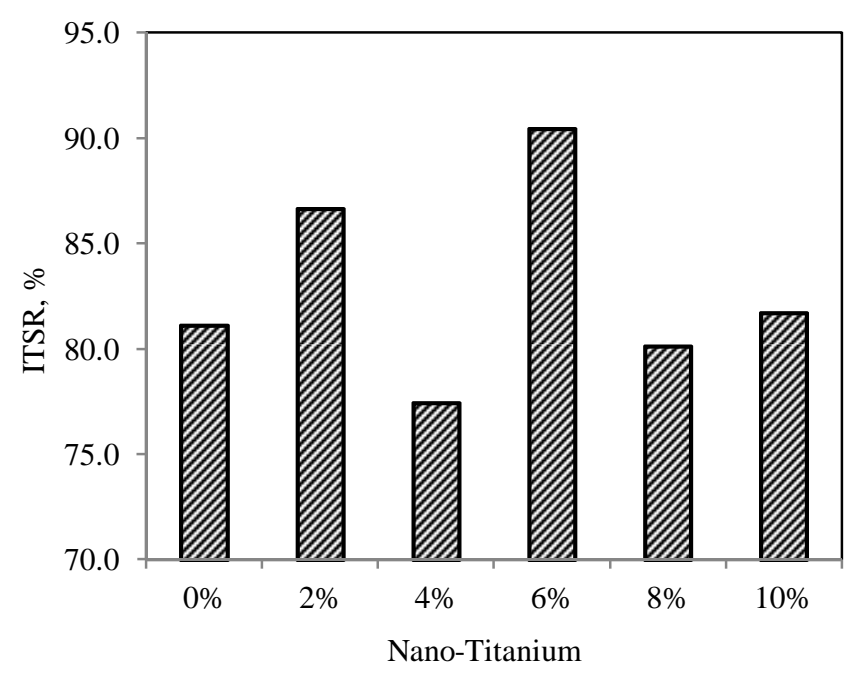

Figure 4: Effect of binder content on resistance of moisture susceptibility 


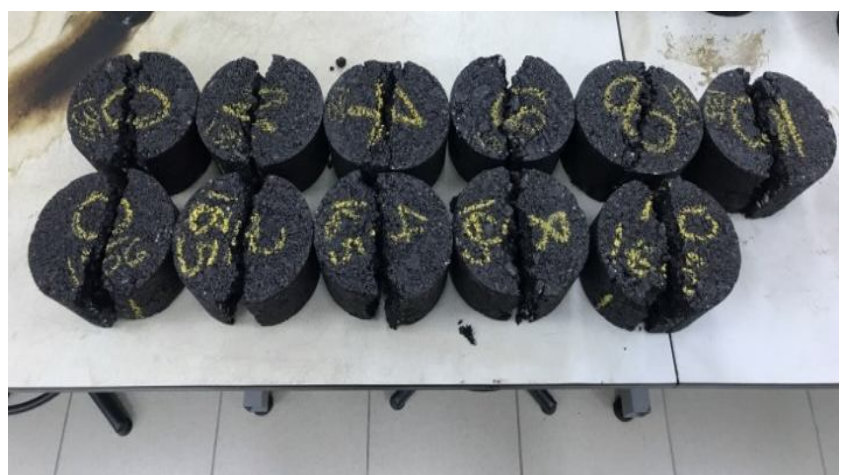

Figure 5: Image of compacted dry and wet specimens

Figure 5 shows the type of failure based on the failure occurred when maximum load was applied to the modified asphalt when testing. Besides that, the visual ratings of tensile strength specimen are based on the scale between $0-5$, where 0 representing no stripping and 5 representing severe stripping. Based on overall observations, more of the sample was in range 3 where the sample had combination type of failure (clear tensile break and deformation).

\section{CONCLUSION}

Based on the test results presented, the following findings and conclusions can be deduced with respect to the applications:

- The addition of modified nano- $\mathrm{TiO}_{2}$ has significantly improved the penetration and softening point of the bitumen. This demonstrated the improvement of stiffness of the binder and also better temperature susceptibility.

- Based from Superpave mix design done with using varies percentage of bitumen to determine the optimum bitumen content. The specimens were followed according to standard specification. From the laboratory test result it can be summarized that with using bitumen content $5.7 \%$ and nano- $\mathrm{TiO}_{2}$ can increase the indirect tensile strength.

- Modified binder with addition of modified nano- $\mathrm{TiO}_{2}$ at each percent is found to have a compaction and mixing temperature is in range of $135^{\circ} \mathrm{C}$ to $165^{\circ} \mathrm{C}$. This is a good sign that the mixture can be made at a lower temperature which in turns will reduce the energy assumption, and thus reduce the greenhouse gases emissions.

- The ITSR results for the dry and wet specimen are complies with the AASHTO T283 because ITSR value exceeds $80 \%$ accept for $4 \%$ where $77.42 \%$. This result may be there were some error occurred during mixed and compacted process. It can be adjusted by repeating the sample preparation included mixing and compaction process for $4 \%$ nano- $\mathrm{TiO}_{2}$. In addition, with using the modified nano- $\mathrm{TiO}_{2}$, it can be concluded that specimens incorporating enhanced the mixes resistance to water.

\section{ACKNOWLEDGEMENT}

The authors wish to thank the Universiti Tun Hussein Onn Malaysia. This study was funding by Ministry of Higher Learning Malaysia under FRGS Grant Vot number 1458.

\section{REFERENCES}

1. Hamzah, M.O.,Aman, M.Y. and Shahadan. (2011) Resistance to Disintegration of Warm Porous Asphalt Incorporating Sasobit. Australian Journal of Basic and Applied Sciences, ISSN 1991-8178, Vol. 5(9), pp: 113-121.

2. Aman, M.Y. and M.O. Hamzah, (2014). Effects of Anti-Stripping Additives on Moisture Sensitivity of Warm Porous Asphalt Mixtures, International Journal of Construction Technology and Management, 1(2): pp. $10-16$

3. Behiry A. E. M., (2013) Laboratory Evaluation of Resistance to Moisture Damage in Asphalt Mixtures, Ain Shams Eng. J., vol. 4, no. 3, pp. 351-363. https://doi.org/10.1016/j.asej.2012.10.009

4. DeDene, C. D., \& You, Z. (2014). The performance of aged asphalt materials rejuvenated with waste engine oil. International Journal of Pavement Research and Technology, 7(2), 145-152. http://doi.org/10.6135/ijprt.org.tw/2014.7(2).145

5. Jahromi, S. G., \& Khodaii, A. (2009). Effects of nanoclay on rheological properties of bitumen binder. Construction and Building Materials, 23(8), 2894-2904. https://doi.org/10.1016/j.conbuildmat.2009.02.027

6. Grant, N. S. F., Hassan, P. I. M., Dylla, H., Cooper, S. B., Mokhtar, A., \& Asadi, S. (2011). A Breakthrough Concept in the Preparation of Highly-Sustainable

7. Kavussi, A., \& Barghabani, P. (2014). The Influence of Nano Materials on Moisture Resistance of Asphalt Mixes, 3, 36-40.

8. ASTM D5. 2005. Standard Test Methods for Penetration of Bituminous Materials. Road and Paving Materials; Vehicle Pavement Systems. Annual Book of American Society for Testing and Materials (ASTM) Standards. West Conshohocken. United States: 19428-2959.

9. ASTM D36. 2005. Standard Test Method for Softening Point of Bitumen (Ring and Ball Apparatus). Annual Book of American Society for Testing and Materials (ASTM) Standards. West Conshohocken United States: 19428-2959

10. Asphalt Institute SP-1 (2003) Super pave Performance Graded Asphalt Binder Specification and Testing, Lexington.

11. Asphalt Institute SP- 2 (2001) Super pave Mix Design Third Edition

12. AASHTO (2007) AASHTO T283: Standard Method of Test for Resistance of Compacted Bituminous Mixture to Moisture Induced Damage, American Association of State Highway and Transportation Officials, Washington D.C

13. Sun, Z., Yi, J., Huang, Y., Feng, D., \& Guo, C. (2016). Properties of asphalt binder modified by bio-oil derived from waste cooking oil. Construction and Building Materials, 102, 496-504.

https://doi.org/10.1016/j.conbuildmat.2015.10.173 